\title{
Suomi.fi - Towards Government 3.0 with a National Service Platform
}

\author{
Jesse Yli-Huumo ${ }^{1}$, Tero Päivärinta ${ }^{2,3}$, Juho Rinne ${ }^{1}$, Kari Smolander ${ }^{4,1}$ \\ ${ }^{1}$ Aalto University, Department of Computer Science, Helsinki, Finland \\ ${ }^{2}$ Luleå University of Technology, Information Systems, Sweden \\ ${ }^{3}$ University of Gothenburg, Department Applied Information Technology, Sweden \\ ${ }^{4}$ Lappeenranta University of Technology, School of Business and Management, Finland \\ \{jesse.yli-huumo, juho.a.rinne@aalto.fi; tero.paivarinta@ltu.se; kari.smolander@lut.fi\}
}

\begin{abstract}
The KaPa (Kansallinen Palveluarkkitehtuuri, in Finnish) program establishes the national e-government service platform in Finland. The platform, Suomi.fi, provides a one-stop portal for citizens and organizations to access both public and related private sector services. This research reports a case study of the platform by analyzing it in light of recent characteristics identified with the emerging concept of Government 3.0: openness and transparency, sharing, increased communication and collaboration, government re-organization through integration and interoperability, and use of new technologies. Our results contribute by concretizing the hitherto abstract and loosely defined concept of Government 3.0 by describing a timely and complex national e-government implementation in detail in light of such characteristics. Our study also suggests three emergent themes in relation to contemporary Government 3.0 characteristics: opening up technologies and solutions in addition to open data, cross-border integration and development, and the enhanced role of the private sector in both development activities and merging into the portfolios of one-stop services.
\end{abstract}

Keywords: E-government, Government 3.0, Platform, Suomi.fi

\section{Introduction}

Digitalization of public services continues. In an ideal scenario, the goal of e-government is to create a seamless architecture for public services, where all systems and services are integrated across both the public and the private sectors to provide a one-stop service $[1,2,3]$ for citizens and organizations. However, while implementing one-stop services have shown to be challenging in municipalities [4] or within particular segments of government alone (e.g. [5]), reaching such a goal at the national level poses even a greater challenge. Indeed, government services may involve several public sector systems and organizations, which need to be re-structured towards increasing interoperability and collaboration [6].

Emerging technologies will change how governments operate and provide services. E-government development is a continuous process of technical and organizational ad- 
vancements, which require transformation of services and organizations $[7,8]$. Currently, advanced e-government services are often based on use of Web 2.0 technologies, and the contemporary solutions are labeled as Government $2.0[9,10]$. Recently, the concept of Government 3.0 has been coined to describe the transformation of the public services to address next generation infrastructures, organizational structures, processes and services $[11,12,13]$. However, the concept remains still quite unclear, while it has been argued, in general, to promote openness, sharing, increased communication and cooperation in the public sector for citizens, businesses and non-governmental stakeholders $[11,12]$.

The characteristics of Government 3.0 continue to emerge without clear definitions, which represents a research gap in contemporary e-government research. Meyerhoff Nielsen [13] argues that with such emerging understanding of Government 3.0, it is not yet possible to evaluate whether individual governments are reaching or have reached the 3.0 stage. This calls for more research on examples of recent e-government projects aiming at Government 3.0 -related characteristics.

In Finland, which often scores high in international e-government rankings, a majority of the public services are digital, accessible, and widely used by citizens [14]. Finland has a long history with e-government. For example, all branches of the government developed their own systems in the 1970s and the Internet was taken into governmental use already in the 1990s [15]. However, in Finland, alike in many other countries, the implementation of the one-stop service at the national government level has been delayed because of lack of service interoperability and integration.

To address the lack of integration and interoperability and the need to develop a onestop service for citizens and organizations, the government of Finland started the KaPa (Kansallinen Palveluarkkitehtuuri, in Finnish, National Service Architecture) program in 2014. The main objective was to develop a national architecture for digital services. In this paper, we study the KaPa program and the service platform Suomi.fi developed within the program. Our objective is to understand and explore the impact of the KaPa program to e-government in Finland, and identify characteristics of Government 3.0 in relation to the on-going development. Our research question is "How do the KaPa program and the Suomi.fi service platform promote Government 3.0 in Finland?"

\section{Background}

Since the mid-2010s, the notion of "Government 3.0" has emerged among policy-makers as a label for next generation ICT-enabled technology innovation and as the successor for "Government 2.0" initiatives [16]. Whereas Government 2.0 refers to the use of Web 2.0 technologies by government $[9,10]$, Government 3.0 embraces the capture of next generation infrastructure, organizational structures, process and services required for the transformation of the public sector [13]. However, the challenge with Government 3.0 as a concept is its current loose definition [13]. A recent literature review on e-government maturity models [13] defines Government 3.0 (building on [11] and [12]) as: "Through openness, sharing, increased communication and cooperation the public 
sector, citizens, businesses and non-governmental stakeholders, the aim is for government to be more service-oriented, competent, and transparent, to proactively provide personalized and customized public services and generate new jobs in a creative manner by opening and sharing government-owned data to the public and encouraging communication and collaboration between government departments".

The current definitions for Government $3.0[11,12,13]$ seem to be divided into two main perspectives. The first perspective regards use of new technologies as the next generation infrastructure, beyond Web 2.0, to provide better services for citizens and organizations. While an exhaustive list of such emerging technologies remains undone, the mentioned examples include artificial intelligence, semantic web and text analytics, machine learning, internet of things, blockchain, and big data analytics $[11,12,13]$. The second perspective is the reorganization of government at several levels. The levels mentioned are infrastructure, organizations, structures, processes and services. Reorganization seems to have two main goals: To increase collaboration and communication within the public sector organizations to remove unnecessary complexity, and to increase openness and transparency of government through concepts such as open data. For a country to reach the "Government 3.0 stage", it is presumably required to take these two aspects in consideration when improving the e-government. Personalized and customized e-government services for the public sector, citizens, businesses and nongovernmental stakeholders to gradually reach a one-stop e-government service, should be included in Government 3.0 initiatives. These concepts are currently presented at an abstract level and do not include detailed definitions or descriptions or the particular elements (cf. [13]). However, we drew upon the initial works on Government 3.0 above and formed the following characteristic categories to be used as a conceptual lens on a large-scale national e-government program:

- Openness and transparency of government and development

- Sharing of data

- Increased communications and collaborations G2C, G2B, and G2G

- Reorganization of government through integration and interoperability

- Use of new technologies

\section{$3 \quad$ Research process}

Our research is a qualitative, exploratory case study on the KaPa program and Suomi.fi. In our view, $\mathrm{KaPa} / \mathrm{Suomi}$.fi represents a rare case [18] of a national, complex program of developing one-stop services for citizens and organizations. We collected data through interviews, survey, observation, and secondary data collection. Firstly, we interviewed $11 \mathrm{KaPa}$ stakeholders. These included KaPa program management, Suomi.fi development team, public sector organizations, and private organizations representing early adopters of the platform. The interviews, which took about one hour each, were recorded and transcribed. Secondly, we performed an online survey in September 2017 with Suomi.fi service platform user organizations (both public sector and private sector). We received 82 responses. The survey was structured regarding experiences with 
each Suomi.fi service and included questions about general opinions on $\mathrm{KaPa}$ as a program. Third, we decided to collect secondary data from news articles and blog posts that were written about KaPa program and Suomi.fi. The number of collected secondary data was +300 items. Last, we took part into two KaPa events to observe stakeholders in the program. The first event was a presentation of online survey results to the Suomi.fi development organization, which also involved two hours of evaluative discussion. The second event was a roadmap event organized by the Suomi.fi development organization to user organizations.

The interviews and events were recorded and transcribed. All data from the interviews, events, survey and news articles and blogs were stored into a database. Two researchers performed data analysis by going through the collected data and creating codes, labels and categories with sticky notes based on collected data. The survey was originally designed for other study, which meant that some of the analyzed data did not have relevance to Government 3.0 concept. After the coding stage and several brainstorming sessions, the identified categories were summarized into higher level themes. While many of the identified themes coincided with the previously (loosely) defined characteristics of Government 3.0 (see Section 2), we wanted also to remain open for potentially emerging themes when analyzing the data. The results thus involve a description of five characteristics of Government 3.0 based on the previous literature and three emerging themes (Table 2; the emerging characteristics and themes marked with *).

\section{$4 \quad$ Results}

\subsection{National Architecture Program in Finland}

The Finnish Government initiated the KaPa program in 2014 (budget: 100 million euros) to develop the national architecture for digital services. The main objective was a compatible infrastructure facilitating information transfer between organizations and services. The KaPa program involves a national data exchange layer (based on the $\mathrm{x}$ Road solution used in Estonia [17]); a shared service view required by citizens, companies and authorities; a new model of nation-wide e-identification, and national solutions for the administration of roles and authorizations for organizations and individuals. Suomi.fi is the name of platform and portal where citizens and organizations can access the digital services. The domain (www.suomi.fi) already existed before the KaPa -program, but the previous version served mostly as an information ledger for citizens and organizations to retrieve basic information about public services or forms to fill in. The architecture of Suomi.fi comprises four layers: data, service, interface, and consumer (Figure 1).

The data layer comprises data registries integrated to the data exchange layer (of the service layer). The data layer is divided further into basic information registries and industry data registries. Basic data registries include key data repositories of the public sector, which are essential for the society to function, such as those of population, property, companies, communities etc. Industry data registries involve information generated by various industries, both public and private. Integration to the data exchange 
layer service provides a standardized and secure platform for data exchange among the public and private organizations.

The service layer involves generic services provided through the platform to increase efficiency and innovation in the public sector and in the related private endeavors. The layer involves no end-user services provided by the public and private organizations themselves (for example, tax office service for tax reporting offered to citizens). The service platform provides eight services for organizations (summarized in Table 1), and coordinates obligations and restrictions on service utilization. Service utilization is free.

The interface layer covers all interfaces for organizations and citizens that are used to access the Suomi.fi services. These interfaces can be divided into two types: programming interfaces and user interfaces. The programming interfaces to access the Suomi.fi services are used by both public and private sector organizations. Avoindata.fi and api.suomi.fi are catalogues that present available application programming interfaces (APIs) for integration in Suomi.fi. Service management is for companies to manage Suomi.fi services. User interfaces are used mostly by citizens and organizations to access Suomi.fi. Web services can be accessed by browser or mobile applications.

The consumer layer connects all users to the Suomi.fi services. Users are divided into two main categories: service providers and ecosystems, and citizens. Service providers and ecosystems include the public sector and private organizations using Suomi.fi. These organizations can be Finnish or from the European Union area. Citizens involve both Finns and other EU citizens, who wish to use the services in Finland.

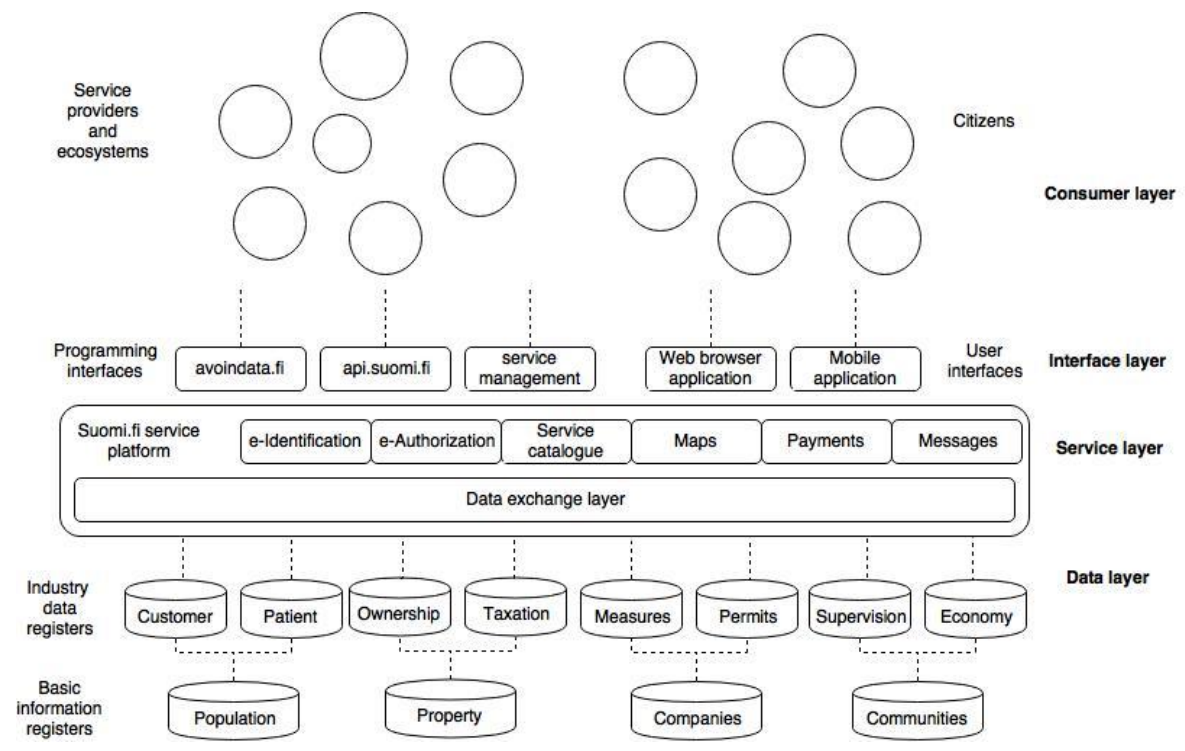

Fig. 1. Suomi.fi architecture 
Table 1. Suomi.fi platform services

\begin{tabular}{|c|c|}
\hline Service description & Avallability \\
\hline $\begin{array}{l}\text { e-Identification enables organizations } \\
\text { to authenticate their service users with } \\
\text { strong electronic authentications meth- } \\
\text { ods; A single sign-on for citizens, which } \\
\text { provides access to all public sector ser- } \\
\text { vices (that use e-Identification). }\end{array}$ & $\begin{array}{l}\text { Public sector organizations are eligible to use the } \\
\text { service (organizations that require strong authen- } \\
\text { tication are obligated by law). In principle, private } \\
\text { sector organization do not have a right to use e- } \\
\text { Identification service, unless they provide ser- } \\
\text { vices to public sector. }\end{array}$ \\
\hline $\begin{array}{l}\text { e-Authorization enables citizens or or- } \\
\text { ganizations to authorize another citizen } \\
\text { or organization to act behalf of them. }\end{array}$ & $\begin{array}{l}\text { Both public and private sector organizations are } \\
\text { allowed to use e-Authorization. }\end{array}$ \\
\hline $\begin{array}{l}\text { The data exchange layer enables stand- } \\
\text { ardized and secured data exchange be- } \\
\text { tween organizations (based on x-Road } \\
\text { [17]). }\end{array}$ & $\begin{array}{l}\text { Both public sector and private sector organiza- } \\
\text { tions are allowed use and provide data (Public or- } \\
\text { ganizations with public data registers are obli- } \\
\text { gated). }\end{array}$ \\
\hline $\begin{array}{l}\text { The service catalogue enables organi- } \\
\text { zations to describe their services in a } \\
\text { standard way to a common database. }\end{array}$ & $\begin{array}{l}\text { blic and private sector organization are al- } \\
\text { to use service. Organizations that produce } \\
\text { services are obligated. }\end{array}$ \\
\hline $\begin{array}{l}\text { jice enables a centralized way } \\
\text { zations and citizens to view } \\
\text { t locations. }\end{array}$ & $\begin{array}{l}\text { organizations are allowed to } \\
\text { ganization are not allowed to } \\
\text { unless they provide service }\end{array}$ \\
\hline $\begin{array}{l}\text { Payments enable public organizations } \\
\text { to send invoices to citizens. Citizens can } \\
\text { access payments through Web portal. }\end{array}$ & $\begin{array}{l}\text { "Vital" -organizations, such as tax office, are ob- } \\
\text { ligated to use the service. Other public sector or- } \\
\text { ganizations are allowed to use the service. Private } \\
\text { sector organization are not allowed to use this ser- } \\
\text { vice, unless they provide services to public sector. }\end{array}$ \\
\hline $\begin{array}{l}\text { Messages are operated to serve citizens } \\
\text { and organizations alike. Citizens can } \\
\text { access messages through Web portal. }\end{array}$ & $\begin{array}{l}\text { Public sector organizations are either obliged or } \\
\text { allowed to use the service (cf. payments). Private } \\
\text { sector organizations are not allowed to use the ser- } \\
\text { vice, unless they provide services to public sector. }\end{array}$ \\
\hline $\begin{array}{l}\text { Web portal is an integrated view on } \\
\text { public services (combining all Suomi.fi } \\
\text { services under one view). Organizations } \\
\text { can provide registers of their web ser- } \\
\text { vices that citizens can view through one } \\
\text { portal. }\end{array}$ & $\begin{array}{l}\text { Public sector organizations are either obliged or at } \\
\text { least allowed to provide registers. Private sector } \\
\text { organization are allowed to use this service, if they } \\
\text { have rights to handle citizens' social security } \\
\text { numbers or business IDs. }\end{array}$ \\
\hline
\end{tabular}

\subsection{KaPa Program in Light of Government 3.0}

Table 2 summarizes our analysis of the Kapa program under the themes of the previously described Government 3.0 characteristics (Section 2) and three new emerging themes (marked with *). One of the new themes, openness of source code, is discussed an already existing Government 3.0 characteristic (openness and transparency).

Table 2. Government 3.0 themes in $\mathrm{KaPa}$

\begin{tabular}{l}
\hline Openness and transparency \\
\hline Public sector organizations databases and registries opened for the public; *Source code \\
available at GitHub for anyone to freely review, copy and use; Suomi.fi development process \\
\hline
\end{tabular}


is transparent to the public through continuous updates with news and blogs from the development team; API catalogues available on the Internet for the public.

\begin{tabular}{|c|}
\hline Sharing \\
\hline $\begin{array}{l}\text { h- } \\
\text { he }\end{array}$ \\
\hline Increased communication and collaboration \\
\hline $\begin{array}{l}\text { Government-to-citizens: Before } \mathrm{KaPa} \text {, Suomi.fi was only an information ledger and citizens } \\
\text { needed to access governmental services through a plethora of separate portals and web sites. } \\
\text { The new Suomi.fi is a personalized and customizable one-stop service for citizens with a sin- } \\
\text { gle sign-on to public services. Government-to-businesses: Before KaPa, Suomi.fi was only } \\
\text { an information ledger and included some forms and documents needed to start or run a busi- } \\
\text { ness. New Suomi.fi provides opportunities for businesses on leveraging free public admin- } \\
\text { istration databases and services to innovate new services. Government-to-government: Be- } \\
\text { fore KaPa, the public sector organizations operated in several separate networks. New Su- } \\
\text { omi.fi provides data sharing and interoperability of information systems across the public ad- } \\
\text { ministration. }\end{array}$ \\
\hline Reorganization of government \\
\hline $\begin{array}{l}\text { Before } \mathrm{KaPa} \text {, e-government consisted of independent components and infrastructure was scat- } \\
\text { tered. With } \mathrm{KaPa} \text {, the production model turns from vertical to horizontal. Service providers } \\
\text { do not need to produce all the layers below the service (such as servers, service capacity, } \\
\text { databases and integration solutions), so the service provider can concentrate on the top layer } \\
\text { (application). Purpose of KaPa is to support the national economy by making public admin- } \\
\text { istration more efficient and by creating new business opportunities in the private sector. }\end{array}$ \\
\hline Use of new technologies \\
\hline $\begin{array}{l}\text { Use of new technologies (those mentioned in the Government } 3.0 \text { literature) was not evident } \\
\text { in the KaPa program. Even though we identified some mentions in our data related to e.g. use } \\
\text { of blockchain or data analytics in e-government services, it was not seen necessarily the main } \\
\text { objective of the KaPa program but more as a task of the future. }\end{array}$ \\
\hline *Cross-border government-to-government integration \\
\hline $\begin{array}{l}\text { The KaPa program involves also an international government-to-government platform inte- } \\
\text { gration with Estonia. The integration between the two platforms represents, to our knowledge, } \\
\text { the first nation-to-nation integration at this level and a step towards Pan-European e-services. }\end{array}$ \\
\hline \\
\hline \\
\hline
\end{tabular}

Openness and transparency. The concept of openness and transparency was mentioned in several data sources. First, the Ministry of Finance of Finland, the responsible entity of $\mathrm{KaPa}$, declared in their program statement that one of the main objectives of $\mathrm{KaPa}$ is to "advance the concept of openness in public sector". In practice, this meant that public databases and registries were opened and made available through the data exchange layer to other public sector organizations and private sector businesses. As 
an example, it is possible to retrieve data about vehicles from Finnish Transport Safety Agency or from a public Finnish trade register that contains information on traders and businesses from Finnish Patent and Registration Office. Currently, the data exchange layer does not yet include all public sector databases and registries. Second, Suomi.fi development was promoted as open source development, which led to making source code of services available freely on GitHub. Anyone can see the source code of services such as X-Road (data exchange layer) and the e-Identification service. Third, the development team provided frequent news and blog posts about the status and development of Suomi.fi concerning the program advancements, schedules, deadlines and challenges, through an information channel called esuomi.fi. Fourth, APIs of Suomi.fi that are available for service developers are listed on public API catalogues in Internet.

Sharing. One of the main goals was to use the Suomi.fi platform as a data exchange layer among the public and private sector organizations alike, which represents an important theme of Government 3.0. All organizations are entitled to join the data exchange layer to use and provide data from registries and databases. According to a development organization representative, the data exchange layer helps retrieve data by applications that need to integrate several data sources. Data exchange enhances efficiency of public services through boosted interoperability. Private businesses can also create new services through open data from the public databases and registries. In the interviews with Suomi.fi user organizations, the data exchange layer was described as " a vital element for interoperability, because otherwise systems wouldn't communicate between each other", or as an interviewee from a private company expressed, "we need data from the basic governmental registries". However, doubts and critique were also expressed. An online survey on the user organizations revealed a few comments such as: "At the moment there are no incentives to join the platform". Many organizations did not yet recognize the business needs and benefits available on the current data exchange platform. One of the reasons might be the current number of organizations joined to the platform (on 22th Feb 2018, the number public and private organizations combined was 81). For example in the Estonian x-Road, the number of active organizations is around 1000 [19]. On the other hand, Suomi.fi is still in an early stage of implementation, and the number of organizations is expected to increase.

Increased communications and collaborations in G2C, G2B, and G2G. A representative of the Ministry of Finance described Suomi.fi as a "Shopping mall for citizens to access public services". The Finnish Government provides Suomi.fi platform and technology (shopping mall), the service providers (both public and private) use Suomi.fi platform to provide the services (shops), and citizens and organizations enter Suomi.fi platform to use provided services (customers). Compared to the previous Suomi.fi, which only served as an information ledger to citizens and businesses, the new Suomi.fi provides increased communication and collaboration between citizens, businesses, and government. The model and platform is expected to implement a customizable and personalizable one-stop service view for citizens and organizations. The new platform is argued to remove the problem where "in every e-government service you need to log in separately, and it is jumping constantly from one place to another" (Manager, Ministry of Finance). The objective of $\mathrm{KaPa}$ is to create gradually a service where all public sector services and many private sector services can be accessed by citizens 
to create a customized and personalized view. "At the end, citizens select, what set of services they want to collect to their service view" (Manager, $\mathrm{KaPa}$ )

Reorganization of government through integration and interoperability. The concept of increased integration and interoperability between government, public sector and private sector systems was a visible theme also in $\mathrm{KaPa}$. "KaPa program fixed the issue of lack of IT-systems integration. One of the most important features of the $\mathrm{KaPa}$ program is the centralized data exchange layer, which means that systems can communicate with each other. This will improve interoperability of public sector systems tremendously" (manager, $\mathrm{KaPa}$ ). Instead of individual point-to-point integrations between systems, the new platform strategy will enhance many-to-many system interoperability. Besides the data exchange layer, also new e-Identification service will increase interoperability among the public sector services. The new Suomi.fi platform enables single sign-on to the services. However, coordination among the service providers and the platform involves also challenges. "One of the challenges of taking service in use is that organizations think that Suomi.fi services are good overall for the public sector, but do not see the need for their own operations" (Manager, KaPa). Therefore, the platform coordinator needs to introduce good support practices to manage change and to gather on-going feedback from the user organizations.

Cross-border government-to-government integration. Finland and Estonia use the same technology (x-Road) for the data exchange layer. The $\mathrm{x}$-Road technology was donated to Finland by Estonia for free and adopted as a basis for Finnish developments. "We are using the software which was originally from Estonia X-road, and have done quite a lot of development on top of it." (Manager, Suomi.fi development). A jointly established institute by Finland and Estonia develops the digital data exchange layer of $\mathrm{x}$-Road technology further. In addition to co-operation in development, the two countries integrate also their very services and data exchange through the joint platform across borders [19]. "Integration makes it possible to exchange data and to use services between two data exchange layers, as fluently as done within Suomi.fi alone" (interviewee, Ministry of Finance). The cooperation between Finland and Estonia can be regarded as a step towards the Pan-European e-services, introducing an interesting aspect of e-government development in the both countries.

Increased private development innovations on public services. E-government is, by definition, mostly associated with the public sector organizations. In this case, however, the role of private sector businesses in the KaPa program and development of the Suomi.fi platform was brought into attention many times. The KaPa program goals stated one of the goals as "making public sector more efficient and creating new business opportunities for the private sector." This notes the current importance of private companies in Finnish e-government. Even though a few services were restricted from the private actors due to legal constraints, such as e-identification, maps, payments, or messages, the data exchange layer, e-authorization and service catalogue represent new opportunities of service innovation to private businesses. These services are free to use, which is expected to attract the private actors as well. The private sector is seen also as a necessary success factor for the platform, "this will only be a good project if private companies decide to join" (Project Leader, Suomi.fi). Moreover, development of Suomi.fi took place in collaboration between public organizations and private companies. 
The KaPa program management was coordinated by the government departments, but the actual development of Suomi.fi platform was mostly conducted by 3rd party development teams. Based on these observations, we regard the role of private sector businesses in e-government development and integrated service delivery as an emerging theme to complement the recent concept of Government 3.0.

\section{Discussion}

Our results suggest two main contributions to the previous literature on the emerging concept of Government 3.0. Firstly, the case analysis showed that the KaPa program and Suomi.fi involve the most conceptual characteristics identified with the recent concept of Government 3.0 (cf. [13]). Hence, we regard Suomi.fi as a rare case which as such illustrates how many of the (hitherto loosely defined) aspects of Government 3.0 can be concretized within a nation-level program and a platform aiming at one-stop public services for citizens and businesses. Especially, our analysis of Suomi.fi illustrates how it concretizes the concepts of openness and transparency, sharing, increased communication and collaboration at different levels of governance interactions (G2C, G2B, G2G), and re-organization of government.

Secondly, our analysis suggests three emergent themes that complement the contemporary characterizations of Government 3.0 (if compared to [13]): 1. Opening technological components and platforms (not just data) of public-sector solutions for further utilization and innovation, 2. cross-border cooperation on service development and integration, and 3. Increasing integration of the private sector in service innovation and delivery; both in development processes and innovations of the platform as such and as introducing a potential solution for private service providers to participate in the service delivery portfolio.

Suomi.fi, together with Estonian x-road, provides an arena for open APIs that enable distributed development and increased contributions from the private sector to service portfolios, and even to the technological infrastructure. In addition to increased data accessibility and open data initiatives this should create a plethora of new innovations on Finnish e-government in the near future. The new level of integration of cross-border collaboration between Finland and Estonia will produce both more efficiency and create also possibilities for new innovative $\mathrm{G} 2 \mathrm{G}$ interactions. Moreover, the private involvement was seen as a crucial success factor for future success of the platform. While we argue that our research contributes by identifying these three themes and discussing about them in the Finnish context, there exists a good number of new research avenues on both organizational and technological advancements in government, as well as the socio-political impacts of such developments over time. Such developments should be analyzed simultaneously from several viewpoints of political, organizational, and technological opportunities and challenges, which will most likely only start to emerge.

The current Suomi.fi concept includes few or no signs of "new technologies" as envisioned in the contemporary ideas of Government $3.0[12,13]$. Hence, we do not yet claim that Suomi.fi would fully represent Government 3.0 in the Finnish context. However, we see the platform and portal development rather as an enabling step towards such developments and predict that the technologies mentioned in the contemporary 
Government 3.0 literature will be increasingly adopted, and enhanced by the integration platforms such as Suomi.fi, if taken into use. For example, data integrations across government agencies provide new opportunities to apply artificial intelligence, semantic web and text analytics, machine learning and big data analytics -related technologies for innovating new services and knowledge building on the public data. IoT-based services and subsequent data exchange integrate ever better to the standardized service platforms, and a whole cluster of new innovative stakeholders can take part on dynamic service development with openly available new technologies and data.

According to our analysis, Finland has thus taken steps with the KaPa program towards Government 3.0. However, there are also other leading-edge national e-government countries such as Estonia [17], Norway [20], Netherlands [20], South Korea [9,12] and many others. To address future research avenues, more in-depth cross-border comparisons and validations for a stage model for Government 3.0 are required. We believe that the future research needs to focus on following the adoption and impact of new technologies in connection to integrated and interoperable national e-government solutions. Time will tell how control and coordination mechanisms for both increased crossborder (e.g., Pan-European) cooperation and seemingly increasing private sector involvement blurring the borderlines between the public and the private in some countries become implemented. In this regard, a thorough political debate on the eventual political consequences of the increased service and information processing integration across the national as well as public-private borderlines needs to continue.

\section{Conclusions}

Government 3.0 has been coined to describe the next generation transformation of egovernment. The case study on Suomi.fi illustrated how many of the hitherto loosely defined characteristics of the Government 3.0 concept were concretized in the Finnish context. In addition, the results suggests three emergent themes to be scrutinized in Government 3.0 initiatives: opening up technologies and solutions in addition to open data, cross-border integration and development, and the enhanced role of the private sector in both development activities and merging into the portfolios of one-stop services. However, we did not identify signs of new technologies, such as AI, machine learning and data science, as envisioned in the contemporary concept of Government 3.0. We argue that an integrated service platform, such as Suomi.fi, could be seen as an enabler for adoption of new technologies and thus a necessary step on the way towards Government 3.0. For future research, we call for more in-depth comparisons of cases and validations for a stage model for Government 3.0 and analyses of the impact and success of new technologies in connection to integrated and interoperable national (and eventually, international) e-government solutions.

\section{References}

1. Layne, K. Lee, J.: Developing fully functional E-government: A four stage model. Gov. Inf. Q., vol. 18, no. 2, pp. 122-136 (2001). 
2. Tat-Kei Ho, A.: Reinventing Local Governments and the E-Government Initiative. Public Adm. Rev., vol. 62, no. 4, pp. 434-444 (2002).

3. Gouscos, D. Kalikakis, M. Legal, M. Papadopoulou, S.: A general model of performance and quality for one-stop e-Government service offerings. Gov. Inf. Q., vol. 24, no. 4, pp. 860-885 (2007).

4. Signore, O. Franco, C. Maurizio, P.: E-government: challenges and opportunities. Proc. CMG Italy XIX Annu. Conf., pp. 1-16 (2005).

5. Schuppan, T. Koehl, S.: One Stop Government: Stalled Vision or a Matter of Design? Empirical Findings from Social Services in Germany (2017).

6. Yannis, C.: Interoperability in Digital Public Services and Administration: Bridging E-Government and E-Business: Bridging E-Government and E-Business. IGI Global (2010).

7. Andersen, K. V. Henriksen, H. Z.: E-government maturity models: Extension of the Layne and Lee model. Gov. Inf. Q., vol. 23, no. 2, pp. 236-248 (2006).

8. Lee, J.: 10year retrospect on stage models of e-Government: A qualitative meta-synthesis. Gov. Inf. Q., vol. 27, no. 3, pp. 220-230 (2010).

9. Nam, T.: Government 3.0 in Korea: Fad or Fashion?. in Proceedings of the 7th International Conference on Theory and Practice of Electronic Governance, New York, NY, USA, pp. 46-55 (2013).

10. Sun, P.-L. Ku, C.-Y. Shih, D.-H.: An implementation framework for E-Government 2.0. Telemat. Inform., vol. 32, no. 3, pp. 504-520 (2015).

11. Charalabidis, Y.: What is government 3.0?. Charalabidis Ed Gov. Transform. Yannis Charalabidis Athens (2015).

12. Ministry of Interior Korea.: Government 3.0. Ministry of Interior Korea, Seoul (2016).

13. Meyerhoff Nielsen, M.: Governance Failure in Light of Government 3.0: Foundations for Building Next Generation eGovernment Maturity Models. in Government 3.0 - Next Generation Government Technology Infrastructure and Services, Springer, Cham, pp. 63-109 (2017)

14. European Commission.: eGovernment in Finland, February 2016, Edition 18.0 (2016).

15. Verohallinto.: Verotuksen historiaa Suomessa. Verohallinnon Julk. 38109 (2009).

16. Hassan, I. A. Adegboyega, O. Enabling Gov 3.0 Through Semantic Web, Natural Language Processing and Text Analytics. T-Gov Wrkshop'14 June 12-13 2014 Brunel Univ. Lond. 14, pp. 64-81 (2014).

17. Anthes, G.: Estonia: A Model for e-Government. Commun ACM, vol. 58, no. 6, pp. 18-20 (2015).

18. Yin, R. K.: Case study research: design and methods. Sage Publications (1989).

19. eSuomi.fi.: https://esuomi.fi/suomen-ja-viron-palveluvaylat-liitetty-yhteen-7-2-tietojennopea-ja-luotettava-vaihto-maiden-valilla-nyt-mahdollista. Last accessed 2018/02/08.

20. Aagesen, G. van Veenstra, A. F. Janssen, M. Krogstie, J.: The Entanglement of Enterprise Architecture and IT-Governance: The Cases of Norway and the Netherlands. in 2011 44th Hawaii International Conference on System Sciences, 2011, pp. 1-10 (2011). 